
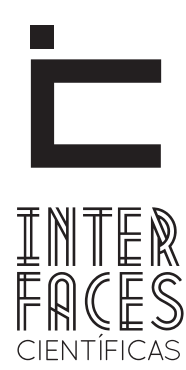

DIREITO

\title{
DINAMOGENESIS DOS DIREITOS HUMANOS E A LEI MARIA DA PENHA ENQUANTO INSTRUMENTO DO PRINCÍPIO DA ISONOMIA
}

HUMAN RIGHTS DINAMOGENESIS AND THE MARIA DA PENHA LAW'S AS INSTRUMENT OF THE EQUALITY PRINCIPLE

DINAMOGENESIS DERECHOS HUMANOS Y EL LEY MARIA DA PENHA COMO INSTRUMENTO PRINCIPIO DE LA IGUALDAD

\section{RESUMO}

O presente artigo busca analisar a Lei 11.340/2006, mais conhecida com Lei Maria da Penha, a qual adentrou o ordenamento jurídico com o intuito de aumentar as medidas protetivas nos casos de violência doméstica, bem como ampliar a punição daqueles que agredissem domesticamente a mulher. Importante, ainda, destacar que o estudo vislumbra tal lei sob o prisma do processo de dinamogenesis dos Direitos Humanos. O trabalho, ao analisar a referida legislação, busca verificar se ela estaria em consonância com o princípio da isonomia, previsto no artigo $5^{\circ}$, caput, da Carta Maior, bem como a suposta inconstitucionalidade por não ser a lei aplicada, via reflexa, às pessoas do gênero masculino.

\section{PALAVRAS-CHAVE}

Lei Maria da Penha. Princípios Constitucionais. Direitos Humanos. Princípio da Isonomia. Princípio da Dignidade da Pessoa Humana. 


\section{ABSTRACT}

This paper analyzes the Law 11.340 / 2006, more known as Maria da Penha Law, which entered the legal system in order to increase protective measures in cases of domestic violence and to increase the punishment of those who strike domestically the woman. Also important to highlight that the study envisions such a law in the light of the process of dinamogenesis of Human Rights. The study, to analyze the legislation, seeks to ensure that it would be in line with the principle of equality under

\section{RESUMEN}

En este artículo se pretende analizar la Ley 11.340 / 2006, conocido a Maria da Penha Ley, que entró en el sistema jurídico con el fin de aumentar las medidas de protección en casos de violencia doméstica, así como aumentar el castigo de los que el país agredissem mujer. También es importante destacar que el estudio prevé una ley de este tipo a la luz del proceso de dinamogenesis de los Derechos Humanos. La obra, mediante el análisis de la legislación, busca asegurar que estaría en línea
Article 5, caput, at the Constitucional Law and the alleged unconstitutionality by law not be applied to the males.

\section{KEYWORDS}

Maria da Penha Law. Constitutional Principles. Human Rights. Principle of equality.Principle of human dignity.

con el principio de igualdad establecido en el artículo 5, caput, Carta Maior, así como la supuesta inconstitucionalidad no sea la ley aplicable, vía refleja, la gente masculina.

\section{PALABRAS CLAVE}

Ley Maria da Penha. principios constitucionales. Derechos humanos. Principio de igualdad. Principio de la dignidad humana. 


\section{INTRODUCÇÃO}

Com a inserção da Lei 11.340, de 7 de agosto de 2006, no ordenamento jurídico brasileiro, houve uma mudança radical do panorama feminino nos casos de violência doméstica. Os crimes nestes casos, até então anteriormente vistos sob o prisma da igualdade no ponto punitivo, passaram a receber um novo enfoque pelo legislador, aumentando-se as possibilidades de sanção existentes.

A entrada em vigor da Lei Maria da Penha foi muito festejada por diversos setores da sociedade em função do maior rigor pelo qual o agressor passou a ser tratado. Todavia, desde a sua concepção, iniciou-se um forte processo de discussão a respeito de sua constitucionalidade, pois em seu texto menciona-se, apenas, a mulher, o que poderia contrariar o princípio da isonomia consagrado no caput do artigo $5^{\circ}$ da Carta Maior.

0 objetivo geral da pesquisa é ressaltar a importância da Lei Maria da Penha. Os objetivos específicos são de verificar a Lei Maria da Penha sob seu aspecto dinamogênico e consagrá-la enquanto instrumento de alcance do princípio da isonomia formal e material.

Neste sentido, o problema levantado na pesquisa seria justamente de verificar se o princípio da isonomia, por meio da dinamogenesis dos Direitos Humanos, tornaria constitucional ou inconstitucional a Lei Maria da Penha. O presente artigo utilizou do método hipotético-dedutivo e de uma análise revisional para alcançar tal tarefa.

\section{BREVE HISTÓRICO DA ORIGEM DA LEI MARIA DA PENHA}

Todos os dados históricos constantes no presente tópico foram extraídos da obra de Maria Berenice Dias (2007).

A Lei no 11.340, de 7 de agosto de 2006, conhecida como Lei Maria da Penha, surgiu após um período de grande discussão social, em decorrência dos horrores sofridos pela biofarmacêutica Maria da Penha Maia Fernandes, na constância de seu casamento.
Em 1983, Maria da Penha sofreu, de seu então marido, Marco Antonio Heredia Viveros, colombiano naturalizado brasileiro, professor universitário e economista, duas tentativas de homicídio. No dia 29, do mês de maio de 1983, Marco simulou um assalto durante a noite e, enquanto sua esposa dormia, atirou nela com uma espingarda.

Após uma semana, durante o banho, Marco tentou eletrocutá-la. Após todas as agressões, Maria da Penha tornou-se paraplégica.

Em função dos diversos tipos penais cometidos, Marco foi denunciado em 1984. Em 1991, o tribunal do júri o condenou em oito anos de prisão. Em sequência, após recurso formulado, o julgamento foi anulado. Posteriormente, passada já mais de uma década dos fatos, em 1996, houve sua condenação. Após recorrer em liberdade, acabou preso em 2002, cumprindo apenas dois anos de sua sentença em regime fechado.

A repercussão negativa do caso foi tão grande que o Centro pela Justiça e o Direito Internacional (CEJIL) e o Comitê Latino-Americano e do Caribe para a Defesa da Mulher (CLADEM) formalizaram a denúncia contra o Brasil, após o relato realizado por Maria da Penha Maia Fernandes.

Posteriormente ao julgamento, o Estado brasileiro foi condenado no valor de 20 mil dólares pela negligência e omissão em relação aos casos de violência doméstica. 0 valor, muito embora significativo no plano de demonstrar a necessidade de mudança de postura, sequer foi suficiente para arcar com as custas processuais. Ademais, ordenou-se que se adotassem medidas que dessem celeridade ao andamento de tais processos.

Apenas após mais de duas décadas dos fatos narrados, em função da pressão internacional sofrida e do clamor popular em relação a tão horrenda agressão, a Lei de violência doméstica acabou sendo sancionada, em 7 de agosto de 2006, pelo então presidente Luis Inácio "Lula" da Silva, e entrou em vigor à partir de 22 de setembro de 2006. Logo após a entrada em vigor da lei Maria da Penha, as denúncias nas delegacias cresceram consideravelmente (SALLES, 2009).

A grande divulgação da mídia sobre o tema, em meados de 2006, pode ser destacada como um dos principais aspectos responsáveis pelo aumento dos 
registros. 0 maior acesso à informação resultou em uma perda considerável de medo em relação à situação pós-denúncia, uma vez que se veiculava que o agressor poderia receber uma ordem de manter distância da vítima, o que apenas demonstra como é necessário que o tema continue a ser explorado de forma constante.

\section{ABRAGÊNCIA E NOVOS PANORAMAS}

0 artigo $7^{\circ}$ da Lei $n^{0} 11.340 / 06$ procurou proteger as mulheres de qualquer forma de violência sofrida. Para tanto, ao enumerar violência física, psicológica, sexual, patrimonial e moral, fez em rol aberto, de modo que se poderia ampliá-lo conforme o que fosse constatado no caso concreto.

Como forma de garantir a proteção de maneira mais abrangente possível, o artigo $5^{\circ}$ da referida Lei estendeu o conceito de violência doméstica, considerando que a Lei aplicar-se-á mesmo que não exista coabitação, bastando apenas que exista uma relação íntima de afeto. Desta forma, a Lei pode ser aplicada nos mais variados casos, não só no vínculo entre marido e mulher, mas também na relação entre namorados, pais, irmãos, primos, dentre outros.

Ademais, ao enunciar em seu artigo $5^{\circ}$, Parágrafo Único, que "as relações pessoais enunciadas neste artigo independem de orientação sexual", o legislador buscou que a lei fosse aplicada nas relações entre lésbicas, travestis, transexuais e outros, desde que mantivessem relação afetiva (BRASIL, 2006). Percebe-se, portanto, que a abrangência da Lei Maria da Penha, desde que constatada violência contra a mulher, dá-se de forma mais ampla possível, em virtude do seu caráter protetivo.

Nesta toada, não se pode olvidar a mudança relacionada à espécie de ação penal prevista na Lei 11.340/06. A referida legislação prevê em seu artigo 16 que a renúncia da até então ação penal pública condicionada pela representação da vítima só poderia ser feita em frente ao juiz, em momento anterior ao oferecimento da denúncia e ouvido o ministério público (BRASIL, 2006).
Em decorrência do referido dispositivo legal, muitas mulheres, coagidas pelo ofensor, ou até resignadas com a situação e temerosas pelo que porventura poderia vir a ocorrer em âmbito penal com seus agressores, desistiam da representação, tornando o crime impune, movimentando inutilmente a máquina Estatal.

Diante da situação atestada, foi proposta pelo então Procurador Geral da República, Roberto Gurgel, a Ação Direta de Inconstitucionalidade 4424, no sentido de declarar inconstitucional o aludido dispositivo, afastando, no tocante à representação, a incidência da Lei do Juizado Especial Criminal (regido pela Lei 9.099/95), tornando pública e incondicionada a ação penal dos crimes previstos na Lei Maria da Penha.

Publicado o resultado do seu julgamento no Diário de Justiça Eletrônico ao primeiro dia de agosto de 2014, a Ação Direta de Inconstitucionalidade foi, por maioria de votos, julgada procedente, sendo voto vencido o ministro Cezar Peluso, o qual proferiu voto no sentido de que, sendo a ação pública incondicionada, a vítima se sentiria deveras inibida em dar a notícia-crime.

Inobstante a posição do ministro Peluso, tal argumento, caso prevalecesse, enfraqueceria sobremaneira a dimensão e o espírito da Lei Maria da Penha. Passar-se-ia a dar conotação diversa àquela pretendida pelo legislador, por possuir a indigitada lei indubitável intuito de proteger e afastar o agressor da vítima e estabelecer punições efetivas ao agente criminoso, sendo certo que com a inconstitucionalidade do dispositivo declarada pelo Supremo Tribunal Federal, há a direta inserção de freios inibitórios pessoais, preventivos para o agressor, evitando assim o cometimento de novos casos de violência.

\section{A LEI MARIA DA PENHA, SUA DINAMOGENESIS E O PRINCÍPIO DA ISONOMIA}

O presente capítulo objetiva analisar a compatibilidade entre o princípio da isonomia e a Lei Maria da Penha. Para tanto, analisar-se-á as funções dos princípios, bem como da isonomia, de forma que se possibilite verificar se a Lei Maria da Penha desrespeita tal princípio constitucional. 


\subsection{ALGUMAS CONSIDERACÕ̃ES SOBRE OS PRINCÍPIOS}

O vocábulo princípio traz em seu bojo diversas conotações, sendo certo que sua análise é imprescindível para entender o tema em exposição.

Allaôr Caffé Alves (2011, p. 150) tece a seguinte definição:

Princípio, no sentido ontológico, é aquilo pelo que a coisa existe, e, no sentido lógico, é aquilo que nos dá a conhecer os conceitos, as proposições e as inferências de modo coerente, numa articulação ideal correta ou válida. Os princípios, lógicos, portanto, bem refletidos, a par de sua natureza estruturadora do pensamento formal, são dirigentes do conhecimento. (Grifos no original)

Em análise próxima de tal pensar, temos que os princípios, no ramo jurídico, são os carros-chefes, os pontos a serem alcançados por todo o ordenamento. Devem ser vistos como o eixo-motriz que impulsiona o processo legislativo e, via reflexa, enquadram-se e tornam-se os anseios, objetivos e perspectivas da sociedade. Desta forma, uma vez que também está previsto dentro do ordenamento jurídico, tem-se que princípio é uma norma, igualmente às regras, porém com aplicações diversas.

Diferenciando regras e princípios, explicita Gilmar Mendes (2014, p. 85):

Os princípios seriam aquelas normas com teor mais aberto do que as regras. Próximo a esse critério, por vezes se fala também que a distinção se assentaria no grau de determinabilidade dos casos de aplicação da norma. Os princípios corresponderiam às normas que carecem de mediações concretizadoras por parte do legislador, do juiz ou da Administração. Já as regras seriam as normas suscetíveis de aplicação imediata.

Podemos concluir, assim, que enquanto as regras têm efeito imediato, certo e sabido frente à determinada situação, o princípio tem valor ponderativo sobre o tema, podendo ser a ele dado valor imensurável ou ínfimo, ainda que em conflito com outros princípios, diante do caso concreto.

A liberalidade do uso e apuração do valor do princípio é infinitamente maior do que o da regra, a qual por si só é fechada, restando-lhe a hermenêutica para seu melhor entendimento e aplicação. Neste sentido, os princípios são os guias dos institutos jurídicos, devendo servir de parâmetro para a edição, interpretação e aplicação doutras normas jurídicas.

Nota-se que a atuação do princípio é de ser o objetivo valorável maior em um sistema jurídico, perfazendo meta sistêmica seu conjunto, em consequente inviabilidade das regras que contrariem seus preceitos.

Tais entendimentos serão essenciais para, no tópico adiante, verificar a compatibilidade da Lei Maria da Penha com o princípio da isonomia.

\subsection{CONSTITUCIONALIDADE OU INCONSTITUCIONALIDADE?}

Com o advento da Lei Maria da Penha iniciou-se uma forte discussão a respeito de sua inconstitucionalidade. Porém, antes de entrarmos nesse embate, devemos, primeiramente, saber o que é uma lei inconstitucional. Segundo José Joaquim Gomes Canotillo (2007, p. 878) "inconstitucional é toda a lei que viola os preceitos constitucionais".

Tendo em vista o conceito em questão, surge uma dúvida. Ao tratar homens e mulheres de maneira diversa, a Lei Maria da Penha iria contra o princípio da isonomia previsto no artigo $5^{\circ}$, caput, da Carta Magna?

Essa pergunta, enquanto realizada sobre diversos valores presentes dentro do princípio da isonomia, pode levar a duas respostas. A primeira resposta se dá caso argumente-se que o homem, também, pode ser vítima da violência e que, nestes casos, existiria a possibilidade de considerá-la inconstitucional, uma vez que tutelaria a mesma situação, em função apenas da inversão de papéis, de forma diversa. No entanto, construir um discurso eloquente no qual o princípio insculpido na Constituição Federal considera homens e mulheres iguais em direitos e obrigações, o que impossibilitaria que a Lei Maria da Penha em sua redação tutelasse apenas o direito das mulheres, é simples, contudo, superficial.

Todos os direitos fundamentais - o que inclui o próprio princípio da isonomia - são interpretados e moldados conforme os anseios e necessidades 
sociais na busca por uma sociedade mais fraterna. Neste sentido, ensina Celso Antonio Bandeira de Mello (2010, p.17), que "qualquer elemento residente nas coisas, pessoas ou situações, pode ser escolhido pela lei como fator discriminatório, donde se segue que, de regra, não é no traço de diferenciação escolhido que se deve buscar algum desacato ao princípio isonômico". Falar em igualdade não significa, portanto, apenas e tão somente, pressupor sua existência, mas, na verdade, buscar instrumentos que a concretizem e possibilitem sua existência no plano formal e material.

A Lei Maria da Penha é apenas um instrumento na busca de tal igualdade, assim como também são os Estatutos do Idoso e o da Criança e do Adolescente. Em função de todas as barreiras que estes grupos ainda enfrentam na sociedade e da peculiaridade dos seus interesses envolvidos, tais legislações nada mais são do que instrumentos de concretização do princípio da isonomia, assim como também é a Lei 11.340/06.

Ao visualizar a Lei Maria da Penha sob o prisma que até aqui foi traçado, significa também perceber a impossibilidade de sua aplicação analógica aos homens. A seara penal não admite a utilização da analogia para agravar a situação do acusado. Portanto, uma vez que a Lei Maria da Penha possua punições mais gravosas que o Código Penal, não pode ser utilizada quando a mulher for a agressora. 0 primeiro argumento, até para quem entenda pela inconstitucionalidade da Lei Maria da Penha, parece válido, uma vez que a seara penal busca sempre as interpretações mais benéficas para o réu.

É certo que, conforme anteriormente ventilado, o princípio da igualdade tem como objetivo precípuo prover os anseios da sociedade para a promoção de uma sociedade mais justa e fraterna, não sendo outra a razão da necessidade da Lei Maria da Penha. Em consequência, como a segunda resposta, surge inafastável a ideia de que o Estado não poderia continuar cego às agressões sofridas por milhares de mulheres, historicamente subjulgadas por seu gênero.
Contrariar fatos discriminatórios históricos, desta forma, sem punição efetiva àqueles que viessem a cometer crimes de violência doméstica contra a mulher, criaria um Estado cada vez mais afastado da sociedade, e um Estado longe da sociedade torna-se oco, engessado e ineficaz. Não obstante tais afirmações, Celso Antonio Bandeira de Mello (2010, p. 21) assevera que existem três questões para a "identificação do desrespeito à isonomia”, in verbis:

\footnotetext{
a) a primeira diz com o elemento tomado como fator de desigualação;

b) a segunda reporta-se à correlação lógica abstrata existente entre o fator erigido em critério de discrímen e a disparidade estabelecida no tratamento jurídico diversificado;

c) a terceira atina à consonância desta correlação lógica com os interesses absorvidos no sistema constitucional e destarte juridicizados.
}

Desta feita, é necessário analisar: a) a necessidade do critério discriminador; b) a ligação direta entre o supracitado critério e as consequências de sua não-instauração e; c) o ordenamento jurídico dá azo para que o critério discriminador seja efetivado?

Surge, então, o critério discriminador pela lógica exceção da generalidade, devendo ser tal critério erigido com base nas diferenciações de uma coletividade que a tornam, por fatores únicos e determinados (no tema em apreço, o gênero feminino) hipossuficientes perante situações pré-concebidas (a agressão doméstica). Olvidar da necessidade e da constitucionalidade do discrímen utilizado na Lei Maria da Penha, ofenderia não só o princípio da igualdade, mas desprestigiaria sobremaneira o princípio da dignidade da pessoa humana.

Dentro do traçado, também, o princípio da isonomia deve ser visto sob o prisma do processo de dinamogenesis dos Direitos Humanos, ou seja, deve ser compreendido de forma mutável e dinâmica. Portanto, neste sentido, o valor isonomia hoje possibilita a discriminação existente dentro da Lei Maria da Penha. Nas palavras de Vladmir Oliveira da Silveira e Maria Mendez Rocasolano (2010, p. 199) tal processo: 
[...] valioso o valor que fundamenta os direitos humanos (dignidade humana). Reconhecendo como valioso, este valor impulsiona o reconhecimento jurídico, conferindo orientação e conteúdos novos (liberdade, igualdade, solidariedade etc.) que expandirão o conceito de dignidade da pessoa. Essa dignidade, por sua vez, junto ao conteúdo dos direitos humanos concretos, é protegida mediante o processo normativo e institucional representado pelo direito.

Assim, com a evolução da sociedade, bem como com a constatação da necessidade de proteção diferenciada das mulheres, percebe-se que o princípio da isonomia admite tais diferenciações quando visto sob o prisma da dinamogenesis.

Em função das considerações aqui traçadas, ainda, não seria possível inserir o homem no bojo da Lei Maria da Penha, uma vez que tal legislação materializa o princípio da isonomia. Caso tal hipótese seja, algum dia, realizada, estaria eivada, sem maiores dúvidas, de profunda e latente inconstitucionalidade.

\section{CONCLUSÃO}

A Lei Maria da Penha surgiu para tentar proteger a mulher vítima de violência dentro da uma relação afetiva, mesmo que inexista coabitação, procurando protegê-las, independentemente da opção sexual.

Em função deste caráter extensivo e do aumento da punição para os homens, a Lei 11.340/06 poderia ser considerada inconstitucional por supostamente violar o princípio da isonomia. Todavia, diferentemente desta primeira impressão, deve-se perceber que tal legislação apenas busca consagrar a igualdade tanto no plano material quanto formal, de forma que está em consonância com os preceitos previstos dentro do ordenamento.

Portanto, em relação ao levantado como problema da pesquisa, a Lei Maria da Penha está inserida justamente dentro da dinamogenesis do valor igualdade. 0 processo de ampliação e modificação dos Direitos Humanos faz com que o princípio da isonomia seja revisto de forma que se torna possível elaborar a Lei Maria da Penha dentro do prisma constitucional de isonomia.

\section{REFERÊNCIAS}

ALVES, Allaor Caffé. Lógica - pensamento formal e argumentação. 5.ed. São Paulo: Quartier Latin, 2011.

CANOTILHO, José Joaquim Gomes. Direito constitucional e teoria da constituição. 7.ed. Coimbra: Almedina, 2007.

DIAS, Maria Berenice. A Lei Maria da Penha na justiça - a efetividade da Lei 11.340/2006 de combate à violência doméstica e familiar contra a mulher. Porto Alegre: Revista dos Tribunais, 2007.

MELLO, Celso Antônio Bandeira de. 0 conteúdo jurídico do princípio da igualdade. 3.ed. 19 ${ }^{\mathrm{a}}$ tiragem. São Paulo: Malheiros, 2010.

MENDES, Gilmar Ferreira e BRANCO, Paulo Gustavo Gonet. Curso de direito constitucional, $9^{a}$ edição. São Paulo: Saraiva, 2014.

PELICANI, Rosa Benites. A Lei Maria da penha e o princípio da igualdade - interpretação conforme a Constituição. Revista da Faculdade de Direito. 2009.

RODRIGUES, Décio Luiz José. Comentários à nova lei de tóxicos e Lei Maria da Penha - violência doméstica. São Paulo: Imperium, 2007.

SILVEIRA, Vladmir Oliveira da; ROCASOLANO, Maria Mendez. Os direitos humanos: conceitos, significados e funções. São Paulo: Saraiva, 2010. 
Data da submissão: 25 de janeiro de 2017

Avaliado em: 10 de fevereiro de 2017 (Avaliador A) Avaliado em: 22 de fevereiro de 2017 (Avaliador B) Aceito em: 23 de fevereiro de 2017
1 Mestre em Direito pela Universidade Nove de Julho; Especialista em Direito Tributário pelo Instituto Brasileiro de Estudos Tributários; Advogado; Professor de Direito na Universidade Nove de Julho, Central de Concursos e Damásio. E-mail: diogo_bv23@hotmail.com

2 Doutorando em Direito pela Pontifícia Universidade Católica de São Paulo; Mestre em Direito pela Universidade Nove de Julho. Especialista em Direito Civil pela Escola Paulista de Direito; Advogado. E-mail: oscarsilvestre2005@ hotmail.com

3 Especialista em Direito Empresarial pela Escola Paulista de Direito; Advogado. E-mail: guilherme.piccinin@gmail.com 